\title{
The Effects of Vitamin D in Patients with Subacromial Impingement Syndrome
}

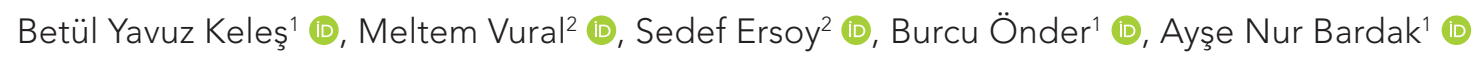 \\ ${ }^{1}$ Department of Physical Medicine and Rehabilitation, University of Health Sciences İstanbul Physical Medicine Rehabilitation Training and Research \\ Hospital, i̇stanbul, Turkey \\ ${ }^{2}$ Department of Physical Medicine and Rehabilitation, University of Health Sciences İstanbul Bakırköy Dr. Sadi Konuk Training and Research Hospital, \\ istanbul, Turkey
}

Cite this article as: Yavuz Keleş B, Vural M, Ersoy S, Önder B, Bardak AN. The Effects of Vitamin D in Patients with Subacromial Impingement Syndrome. JAREM 2019; 9(2): 61-5.

\begin{abstract}
Objective: Vitamin D deficiency can cause pain and disability in many diseases. Subacromial impingement syndrome (SAIS) is a common reason for shoulder pain. In this study, we aimed to assess the relationship between vitamin D and the clinical features in patients with SAIS.

Methods: Patients with SAIS were evaluated, and age, gender, affected side, disease duration, 25-OH vitamin D, and other laboratory tests were recorded from patients' files. Also, patients' data on shoulder visual analog scale (VAS), shoulder range of motions (ROMs), and scores of Disabilities of the Arm, Shoulder, and Hand (DASH) were obtained. The patients were grouped according to their 25-OH vitamin D levels. (Group 1: $<10 \mathrm{ng} / \mathrm{mL}$, Group 2: $10-20 \mathrm{ng} / \mathrm{mL}$, and Group 3: $>20 \mathrm{ng} / \mathrm{mL}$ ). Demographic and clinical features were compared between groups, and the relation of vitamin D with VAS, DASH scores, and ROMs were investigated.

Results: Eighty patients with SAIS were included in the study. The mean age of patients was $51.99 \pm 11.14$ years. There were 35 female and 25 male patients. The mean disease duration was 6.32 months. VAS was statistically higher in Group 1 compared to Group 3. Also, shoulder pain was negatively correlated with $25-\mathrm{OH}$ vitamin D level. There was no statistically significant relation between the $25-\mathrm{OH}$ vitamin D level and DASH score or the $25-\mathrm{OH}$ vitamin D level and shoulder ROMs.

Conclusion: Severe deficiency of vitamin D increases shoulder pain in patients with SAIS. Vitamin D deficiency should be taken into consideration in patients with severe shoulder pain in SAIS.

Keywords: Subacromial impingement syndrome, vitamin D, pain, disability, shoulder
\end{abstract}

\section{INTRODUCTION}

Subacromial impingement syndrome (SAIS) is a common reason for shoulder pain (1). SAIS is a spectrum of pathologies, including subacromial bursitis, rotator cuff tendinopathy, and rotator cuff tears $(2,3)$. SAIS has a progressive pathology in general (4). Bone disorders, muscle weakness, deterioration of the scapula humeral rhythm, poor posture, and inflammation in the bursa are the possible mechanisms of SAIS (2-5). Furthermore, it has been shown that inflammatory cytokines, matrix metalloproteinases (MMPs), and cyclo-oxygenases increased in the subacromial bursa of patients with SAIS and rotator cuff disease $(6,7)$. Therefore, mechanical factors as well as inflammatory processes are involved in the pathophysiology of SAIS (8).

Vitamin D has an important role in the muscle metabolism and functions. It supports protein synthesis and muscle cell growth.
The relation of vitamin $D$ with muscle mass, strength, and functions has been shown in many studies (9-11). Vitamin D deficiency results in degenerative changes in type II muscle fibers, including rotator cuff muscles, and hence muscles tend to tear (12). Vitamin $D$ has an important role in muscle performance. Oh et al. (10) found that vitamin D decreased the fatty degeneration of the supraspinatus and infraspinatus while increasing muscle performance in patients with shoulder problems. It can also have a role in tendon remodeling through MMPs, and low vitamin D level may delay the recovery of rotator cuff tendon repair by upregulating MMP-9 (13-15).

The mechanical factors arising from the musculoskeletal system and various inflammatory mechanisms are responsible for SAIS, as mentioned above. Also, vitamin D has important roles in the musculoskeletal system and inflammatory processes (16). There- 
fore, it would be beneficial to investigate the clinical effects of vitamin D on SAIS. We aimed to investigate the effects of vitamin $\mathrm{D}$ on pain, disability, and shoulder range of motion (ROM) in patients with SAIS.

\section{METHODS}

\section{Subjects}

Patients who were admitted to the physical medicine and rehabilitation outpatient clinic between January 01, 2014 and June 30, 2014 and had shoulder pain due to SAIS were retrospectively assessed in this study. The diagnosis of SAIS was based on the clinical findings and magnetic resonance imaging (MRI). SAIS was defined as positive shoulder tests for painful arc, Neer, and Hawkins tests and subacromial bursitis and/or rotator cuff tendon pathology in MRI. Patients who had a detailed physical examination (shoulder ROMs and positive for painful arc, Neer, and Hawkins shoulder tests), clinic evaluation (shoulder visual analog scale [VAS] disease arm shoulder hand [DASH] score), laboratory tests (liver and renal function tests, calcium, phosphorous, $25-\mathrm{OH}$ vitamin $\mathrm{D}$, and parathyroid hormone [PTH]), and subacromial bursitis and/or rotator cuff tendon pathology in MRI were included in the study.

Patients who had infectious shoulder arthritis, liver and renal function disorders, any rheumatologic (rheumatoid arthritis or spondyloarthropathy) and neurologic disorders, intraarticular fracture, a history of shoulder operation, adhesive capsulitis, calcific tendinitis, tip 3 acromion, bilateral shoulder lesion, full thickness rupture of rotator cuff tendons, and incomplete documentation were excluded.

\section{Procedure}

Age, gender, the affected shoulder side, duration of shoulder pain, shoulder ROMs for abduction, flexion, external rotation and internal rotation, blood level of $25-\mathrm{OH}$ vitamin $\mathrm{D}$, shoulder pain VAS, and DASH scores were recorded. The blood level of $25-\mathrm{OH}$ vitamin $D$ was used to determine the vitamin $D$ level in patients.

Shoulder pain was assessed using VAS $(0-10 \mathrm{~cm}$ scale; 0 means no pain, 10 means severe pain). DASH is a 30 -item questionnaire. It evaluates pain, tingling, stiffness, weakness, social function, work, sleep, and self-confidence in patients (17).

The immunechemiluminometric assay was used to determine the vitamin D level in patients. The serum concentration of PTH was determined using an electrogenerated chemiluminescence immunoassay technology.

Patients were divided into three groups according to previous literature $(18,19)$ : Group 1: $25-\mathrm{OH}$ vitamin $\mathrm{D}<10 \mathrm{ng} / \mathrm{mL}$, Group 2: 25-OH vitamin D 10-20 ng/mL, Group 3: 25-OH vitamin D > 20 ng/ $\mathrm{mL}$. The demographic features, ROMs, VAS, and DASH scores were compared. Furthermore, the correlations of $25-\mathrm{OH}$ vitamin $D$ with ROMs, VAS, and DASH scores were analyzed.

This study was approved by the local ethics committee of Bakirköy Dr. Sadi Konuk Trainining and Research Hospital and was conducted in accordance with the ethical standards in the Declaration of Helsinki.

\section{Statistical Analysis}

The statistical analysis was performed using the Number Cruncher Statistical System 2007 \&PASS (Power Analysis and Sample Size) 2008 Statistical Software (Utah, USA). When data of the study were assessed, descriptive statistics (mean, standard deviation, median, frequency, ratio and minimum and maximum) were reported. In comparison to quantitative data, non-normally distributed variables were compared between the two groups using the Mann-Whitney $U$ test and between two or more groups using the Kruskal-Wallis test. The Spearman's Correlation analysis was performed to assess the relationship of non-normally distributed variables. Results were evaluated at a significance level of a $p<0.05$.

\section{RESULTS}

Eighty patients who met the study criteria were included in this study. The patients' mean age was $51.99 \pm 11.14$ years, and the symptom duration was $6.32 \pm 5.89$ months. There were 55 (68.8\%) female and 25 (31.3\%) male patients. There were $22 \mathrm{pa}$ tients in Group 1, 43 patients in Group 2, and 15 patients in Group 3.

Table 1 shows the comparison of demographic features, shoulder ROMs, VAS, and DASH scores of the three groups. There was a significant difference in VAS between the groups. The shoulder VAS was significantly higher in Group 1 compared to Group 3 ( $p=0.01$ ). No significant difference was observed for shoulder VAS between Groups 1 and 2 or between Groups 2 and 3 . In addition, there was a statistically significant difference in the PTH levels between the groups $(p=0.024)$. According to binary comparisons, PTH in Group 1 was significantly higher than that in Group $3(p=0.005)$. No statistically significant differences were detected for PTH between Groups 1 and 2 or Groups 2 and 3 ( $p>0.05$ ). There was no significant difference in the DASH score and shoulder ROMs between the groups. The correlation analyses of 25-OH vitamin D with shoulder ROMs, shoulder VAS, and DASH scores are shown in Table 2. A significant negative correlation was detected between $25-\mathrm{OH}$ vitamin $D$ and VAS.

\section{DISCUSSION}

The results of this study demonstrated that severe deficiency of vitamin $\mathrm{D}(25-\mathrm{OH}$ vitamin $\mathrm{D}<10 \mathrm{ng} / \mathrm{mL})$ increases shoulder pain in SAIS. In addition, it was observed that shoulder pain increases in SAIS as the level of vitamin D decreases. However, according to our results, there was no relation between vitamin $\mathrm{D}$ and disability or vitamin D and shoulder ROM in SAIS. To the best of our knowledge, this is one of the first studies which investigated the clinical relations between SAIS and vitamin D.

Subacromial impingement syndrome (SAIS) is often accompanied by subacromial bursitis, rotator cuff tendinosis, and tendon tears (2). Subacromial bursitis is the major reason of pain and disability in SAIS (8). It has been shown that inflammatory cytokines (interleukin [IL]-1, IL-6, tumor necrosis factor [TNF- $\alpha$ ]), MMPs, and cyclo-oxygenases increase in the subacromial bursa of patients with SAIS $(6,7,20)$. SAIS and rotator cuff pathologies can be 
Table 1. Demographic and clinical characteristics of groups

\begin{tabular}{|c|c|c|c|c|}
\hline & Group 1 & Group 2 & Group 3 & $p$ \\
\hline Age, years & $47(34-75)$ & $53(24-73)$ & $50(24-69)$ & 0.183 \\
\hline Duration of disease, months & $5(2-24)$ & $4.5(1-36)$ & $6(2-24)$ & 0.417 \\
\hline Affected side, right/left & $14 / 8$ & $23 / 20$ & $9 / 6$ & 0.722 \\
\hline Flexion, degrees & $150(90-180)$ & $140(20-180)$ & $160(90-180)$ & 0,138 \\
\hline Abduction, degrees & $140(60-180)$ & $120(30-180)$ & $150(80-180)$ & 0.157 \\
\hline IR, degrees & $70(40-90)$ & $60(10-90)$ & 70 (30-90) & 0.084 \\
\hline ER, degrees & $60(30-90)$ & $60(15-90)$ & $50(10-90)$ & 0.939 \\
\hline VAS $(0-10)$ & $8(3-10)$ & $7(0-10)$ & $6(0-10)$ & $0.022^{\star}$ \\
\hline DASH & $66(25-102)$ & $78(38-126)$ & $67(41-119)$ & 0.270 \\
\hline PTH (pg/mL) & $50.1(17.9-114)$ & $35.59(18.2-198)$ & $30(22.7-44.1)$ & $0,024^{\star}$ \\
\hline
\end{tabular}

Table 2. Correlation analysis of shoulder roms, VAS, and DASH with 25-oh vitamin D

\begin{tabular}{|l|c|c|}
\hline & \multicolumn{2}{|c|}{$\mathbf{2 5 - O H}$ vitamin D } \\
\hline & $\mathbf{r}$ & $\mathbf{P}$ \\
\hline Flexion, degrees & -0.014 & 0.904 \\
\hline Abduction, degrees & 0.099 & 0.404 \\
\hline IR, degrees & -0.113 & 0.344 \\
\hline ER, degrees & -0.086 & 0.468 \\
\hline VAS & -0.308 & $0.006^{*}$ \\
\hline DASH & 0.065 & 0.574 \\
\hline PTH (pg/mL) & -0.483 & $0.001^{*}$ \\
\hline $\begin{array}{l}\text { ROMs: range of motions; VAS: visual analog scale; DASH: disease arm } \\
\text { shoulder hand score; PTH: parathyroid hormone; IR: internal rotation; ER: } \\
\text { external rotation; }{ }^{*} \text { p }<0.05\end{array}$
\end{tabular}

painful and associated with inflammation $(6,16)$. Particularly, substance P and IL-1 in the subacromial bursa were correlated with pain $(8,20)$. The suppression effect of vitamin $D$ on inflammatory mediators (IL-1 and TNF-a) and MMPs has been reported in previous studies $(13,21-24)$. According to the results of this study, vitamin $D$ is negatively correlated with shoulder pain in SAIS. One of the possible mechanisms may be the suppressive effect of vitamin D on inflammatory cytokines and enzymes. In addition, it was shown that vitamin $\mathrm{D}$ promoted the proliferation of tendonderived cells that were obtained from the supraspinatus muscle (25). Hence, vitamin D has crucial effects on the tendons in the subacromial space. The reduction of vitamin D level in the blood may cause PTH to rise. In this study, PTH is significantly higher in Group 1 than in Group 3. PTH causes weakness of the bonetendon junction by inducing general osteoporosis with subperi- osteal bone resorption (26). Increased PTH in severe vitamin D deficiency may also negatively affect the tendons passing from subacromial space.

Pain due to vitamin $D$ deficiency is usually seen in the low back, pelvis, hip, back, and rib bones (27). The relationship between low vitamin $D$ levels and pain in patients with non-specific musculoskeletal pain has been shown in previous studies (28-31). Also, replacement therapy for vitamin $D$ deficiency improves pain and other musculoskeletal symptoms in patients with widespread pain (31). Vitamin D has important roles in the inflammatory process and musculoskeletal system; therefore, the deficiency of vitamin D may also play role in SAIS, which is closely related with both the systems.

Vitamin $D$ is also one of the most common nutritional deficiencies in the world (32). In this study, vitamin D levels were deficient in $81 \%$ of patients with SAIS. Therefore, low vitamin D levels should be considered for patients who have severe shoulder pain in SAIS.

According to our results, no significant relation was observed between ROMs and vitamin D levels or between disabilities of patients and vitamin $D$ levels. Similar to our results, it has been shown in another study (33) that vitamin D level was not related to the functional status in patients who had undergone an arthroscopic rotator cuff repair. In contrast, Oh et al. (10) reported that there was a negative association between vitamin $D$ level and fatty degeneration of rotator cuff muscles in patients with full-thickness rotator cuff tears versus those with other shoulder lesions without a tear, and they concluded that low serum vitamin $D$ level might have more severe rotator cuff tear. There are conflicting results of studies that have investigated the effects of vitamin D on shoulder pathologies in literature.

To the best of our knowledge, the effects of vitamin $D$ on disability, ROMs, and pain in SAIS have not been investigated previously. This was the primary aim of our study. The study has few limita- 
tions. First, this is a retrospective study and data were obtained from patient records. Secondly, when patients were divided into three groups according to the vitamin D status, the number in Group 3 was less than other groups. The ratio of female and male patient was $68.8 \%$ and $31.2 \%$, respectively, and this difference was similar to a study that investigated the demographic features in SAIS (34). Further studies that investigate the clinical features of SAIS after vitamin D supplements are given will provide more detailed information. Also, it will be useful to investigate the local effects of vitamin D on soft tissues of the subacromial space.

\section{CONCLUSION}

According to our findings, severe deficiency of vitamin $D$ may increase shoulder pain in patients with SAIS. Also, vitamin D level is inversely correlated with shoulder pain in SAIS. Therefore, vitamin $D$ level may be monitored in patients with severe pain due to SAIS.

Ethics Committee Approval: Ethics committee approval was received for this study from the Ethics Committee of Bakırköy Dr. Sadi Konuk Trainining and Research Hospital and authors declared that the research was conducted according to the principles of the World Medical Association Declaration of Helsinki "Ethical Principles for Medical Research Involving Human Subjects", (amended in October 2013).

Informed Consent: Informed consent was not taken from patients due to the retrospective nature of the study.

\section{Peer-review: Externally peer-reviewed.}

Author Contributions: Concept - B.Y.K., M.V., S.E., A.N.B., B.Ö.; Design - B.Y.K., M.V., S.E., A.N.B., B.Ö.; Supervision - B.Y.K., M.V., S.E., A.N.B., B.Ö.; Resources - B.Y.K., M.V., S.E., A.N.B., B.Ö.; Data Collection and/ or Processing - B.Y.K., M.V., S.E., A.N.B., B.Ö.; Analysis and/or Interpretation - B.Y.K., M.V., S.E., A.N.B., B.Ö.; Literature Search - B.Y.K., M.V., S.E., A.N.B., B.Ö.; Writing Manuscript - B.Y.K., M.V., B.Ö.; Critical Review - B.Y.K., M.V., S.E., A.N.B., B.Ö.

Conflict of Interest: The authors have no conflict of interest to declare.

Financial Disclosure: The authors declared that this study has received no financial support.

\section{REFERENCES}

1. Tangtrakulwanich B, Kapkird A. Analyses of possible risk factors for subacromial impingement syndrome. World J Orthop 2012; 3: 5-9. [CrossRef]

2. Harrison AK, Flatow EL. Subacromial impingement syndrome. J Am Acad Orthop Surg 2011; 19: 701-8. [CrossRef]

3. Matsen FA III AC. Subacromial impingement. In: Rockwood CA MFI, editors. The Shoulder. Philadelphia: Saunders; 1990; 623-46.

4. Escamilla RF, Hooks TR, Wilk KE. Optimal management of shoulder impingement syndrome. Open Access J Sports Med 2014; 5: 13-24. [CrossRef]

5. Roddy E, Zwierska I, Hay EM, Jowett S, Lewis M, Stevenson K, et al. Subacromial impingement syndrome and pain: protocol for a randomised controlled trial of exercise and corticosteroid injection (the SUPPORT trial). BMC Musculoskelet Disord 2014; 15: 81. [CrossRef]

6. Voloshin I, Gelinas J, Maloney MD, O'Keefe RJ, Bigliani LU, Blaine TA. Proinflammatory cytokines and metalloproteases are expressed in the subacromial bursa in patients with rotator cuff disease. Arthroscopy 2005; 21: 1076. [CrossRef]

7. Ertan S, Ayhan E, Guven MF, Kesmezacar H, Akgun K, Babacan M. Medium-term natural history of subacromial impingement syndrome. J Shoulder Elbow Surg 2015; 24: 1512-8. [CrossRef]
8. Kim YS, Bigliani LU, Fujisawa M, Murakami K, Chang SS, Lee HJ, et al. Stromal cell-derived factor 1 (SDF-1, CXCL12) is increased in subacromial bursitis and downregulated by steroid and nonsteroidal antiinflammatory agents. J Orthop Res 2006; 24: 1756-64. [CrossRef]

9. Birge SJ, Haddad JG. 25-hydroxycholecalciferol stimulation of muscle metabolism. J Clin Invest 1975; 56: 1100-7. [CrossRef]

10. Oh JH, Kim SH, Kim JH, Shin YH, Yoon JP and $\mathrm{Oh} \mathrm{CH}$. The level of vitamin $\mathrm{D}$ in the serum correlates with fatty degeneration of the muscles of the rotator cuff. J Bone Joint Surg Br 2009; 91: 1587-93. [CrossRef]

11. Visser M, Deeg DJ, Lips P. Longitudinal Aging Study A. Low vitamin $D$ and high parathyroid hormone levels as determinants of loss of muscle strength and muscle mass (sarcopenia): the Longitudinal Aging Study Amsterdam. J Clin Endocrinol Metab 2003; 88: 576672. [CrossRef]

12. Angeline ME, Gee AO, Shindle M, Warren RF, Rodeo SA. The effects of vitamin D deficiency in athletes. Am J Sports Med 2013; 41: 461-4. [CrossRef]

13. Bahar-Shany K, Ravid A, Koren R. Upregulation of MMP-9 production by TNFalpha in keratinocytes and its attenuation by vitamin D. J Cell Physiol 2010; 222: 729-37.

14. Angeline ME, Ma R, Pascual-Garrido C, Voigt C, Deng XH, Warren $R F$, et al. Effect of diet-induced vitamin $D$ deficiency on rotator cuff healing in a rat model. Am J Sports Med 2014; 42: 27-34. [CrossRef]

15. Timms PM, Mannan N, Hitman GA, Noonan K, Mills PG, Syndercombe-Court $D$, et al Circulating MMP9, vitamin D and variation in the TIMP-1 response with VDR genotype: mechanisms for inflammatory damage in chronic disorders? QJM 2002; 95: 787-96. [CrossRef]

16. Dougherty KA, Dilisio MF, Agrawal DK. Vitamin D and the immunomodulation of rotator cuff injury. J Inflamm Res 2016; 9: 123-31.

17. Duger T, Yakut E, Oksuz C, Yorukan S, Bilgutay B, Ayhan Ç, et al. Reliability and validity of the Turkish version of the Disabilities of the Arm, Shoulder and Hand (DASH) Questionnaire. Fizyoterapi Rehabilitasyon 2006; 17: 99.

18. Holick MF. High prevalence of vitamin D inadequacy and implications for health. Mayo Clin Proc 2006; 81: 353-73. [CrossRef]

19. Malas FU, Kara M, Aktekin L, Ersoz M, Ozcakar L. Does vitamin D affect femoral cartilage thickness? An ultrasonographic study. Clin Rheumatol 2014; 33: 1331-4. [CrossRef]

20. Gotoh M, Hamada K, Yamakawa H, Yanagisawa K, Nakamura M, Yamazaki $\mathrm{H}$, et al. Interleukin-1-induced subacromial synovitis and shoulder pain in rotator cuff diseases. Rheumatology (Oxford) 2001; 40: 995-1001. [CrossRef]

21. Laird E, McNulty H, Ward M, Hoey L, McSorley E, Wallace JM, et al. Vitamin $D$ deficiency is associated with inflammation in older Irish adults. J Clin Endocrinol Metab 2014; 99: 1807-15. [CrossRef]

22. Balato A, Schiattarella M, Lembo S, Mattii M, Prevete N, Balato N, et al. Interleukin-1 family members are enhanced in psoriasis and suppressed by vitamin D and retinoic acid. Arch Dermatol Res 2013; 305: 255-62. [CrossRef]

23. Mao L, Ji F, Liu Y, Zhang W, Ma X. Calcitriol plays a protective role in diabetic nephropathy through anti-inflammatory effects. Int J Clin Exp Med 2014; 7: 5437-44.

24. Peterson CA, Heffernan ME. Serum tumor necrosis factor-alpha concentrations are negatively correlated with serum $25(\mathrm{OH}) \mathrm{D}$ concentrations in healthy women. J Inflamm (Lond) 2008; 5: 10. [CrossRef]

25. Maman E, Somjen D, Maman E, Katzburg S, Sharfman ZT, Stern N, et al. The response of cells derived from the supraspinatus tendon to estrogen and calciotropic hormone stimulations: in vitro study. Connect Tissue Res 2016; 57: 124-30. [CrossRef]

26. Abate M, Guelfi M, Pantalone A, Vanni D, Schiavone C, Andia I, et al. Therapeutic use of hormones on tendinopathies: a narrative review. Muscles Ligaments Tendons J 2016; 6: 445-452. [CrossRef]

27. Heath KM, Elovic EP. Vitamin D deficiency: implications in the rehabilitation setting. Am J Phys Med Rehabil 2006; 85: 916-23. [CrossRef] 
28. Plotnikoff GA, Quigley JM. Prevalence of severe hypovitaminosis D in patients with persistent, nonspecific musculoskeletal pain. Mayo Clin Proc 2003; 78: 1463-70. [CrossRef]

29. Lotfi A, Abdel-Nasser AM, Hamdy A, Omran AA, El-Rehany MA. Hypovitaminosis $D$ in female patients with chronic low back pain. Clin Rheumatol 2007; 26: 1895-901. [CrossRef]

30. Azizieh FY, Alyahya KO, Dingle K. Association of self-reported symptoms with serum levels of vitamin $D$ and multivariate cytokine profile in healthy women. J Inflamm Res 2017; 10: 19-28. [CrossRef]
31. Yilmaz R, Salli A, Cingoz HT, Kucuksen S, Ugurlu H. Efficacy of vitamin $D$ replacement therapy on patients with chronic nonspecific widespread musculoskeletal pain with vitamin D deficiency. Int J Rheum Dis 2016; 19: 1255-62. [CrossRef]

32. Hossein-nezhad A, Holick MF. Vitamin D for health: a global perspective. Mayo Clin Proc 2013; 88: 720-55. [CrossRef]

33. Ryu KJ, Kim BH, Lee Y, Dan J, Kim JH. Low Serum Vitamin D Is Not Correlated With the Severity of a Rotator Cuff Tear or Retear After Arthroscopic Repair. Am J Sports Med 2015; 43: 1743-50. [CrossRef] 